RESPIRATORY INFECTION

\title{
Longer term follow up of aerobic capacity in children affected by severe acute respiratory syndrome (SARS)
}

\section{C W Yu, A M Li, R C H So, A McManus, P C Ng, W Chu, D Chan, F Cheng, W K Chiu, C W Leung, Y S Yau, K W Mo, E M C Wong, A Y K Cheung, T F Leung, R Y T Sung, T F Fok}

See end of article for authors' affiliations

Correspondence to: Dr A M Li, Department of Paediatrics, Prince of Wales Hospital, The Chinese University of Hong Kong, Shatin, Hong Kong; albertmli@cuhk.edu.hk

Received 17 May 2005 Accepted 3 January 2006 Published Online First 31 January 2006

Background: A study was undertaken to investigate the aerobic capacity and pulmonary function of children 6 and 15 months after the diagnosis of severe acute respiratory syndrome (SARS).

Methods: Thirty four patients of mean age 14.7 years completed both pulmonary function and maximal aerobic capacity tests at 6 months. All had normal clinical examination and were asymptomatic. Their exercise responses were compared with a group of healthy controls. Complete data were collected on 27 of the original 34 cases at 15 months.

Results: Compared with normal controls, the patient group had significantly lower absolute and mass related peak oxygen consumption (peak $\mathrm{VO}_{2}(p<0.01)$ ), higher ventilatory equivalent for oxygen $(p<0.01)$, lower oxygen pulse $(p<0.01)$, and a lower oxygen uptake efficiency slope $(p<0.01)$ at 6 months. This impairment was unexpected and out of proportion with the degree of lung function abnormality. Residual high resolution computed tomography of thorax (HRCT) abnormalities were present in 14 patients. Those with abnormal HRCT findings had significantly lower mass related peak $\mathrm{VO}_{2}$ than subjects with normal radiology $(p<0.01)$. Absolute and mass related peak $\mathrm{VO}_{2}$ in the patient group remained impaired at 15 months despite normalisation of lung function in all patients.

Conclusions: The mechanism for the reduced aerobic capacity in children following SARS is not fully understood, but it is probably a consequence of impaired perfusion to the lungs at peak exercise and deconditioning.

S evere acute respiratory syndrome (SARS) is a contagious respiratory infection caused by the SARS coronavirus (SARS CoV). ${ }^{1}$ In adults a mortality rate of around $10 \%$ has been reported, and pulmonary complications in the form of pulmonary fibrosis and bronchiectasis may be as high as $20 \%$ in survivors. ${ }^{2}$ A number of adult patients complained of limitations in physical function from general weakness and/or shortness of breath after recovery from the disease. ${ }^{3}$ The disease spectrum and progression are, however, different in children. No fatalities were reported in children and the clinical course and radiological changes were much milder. ${ }^{4-6}$ Six months after diagnosis, all 47 children with SARS had complete clinical recovery and $>90 \%$ had normal lung function. ${ }^{7}$

The individual response to exercise is an important clinical assessment tool since it provides a composite evaluation of the respiratory, cardiac, and metabolic systems. Exercise testing is thus a more reliable assessment method of functional outcome than resting pulmonary function tests. Aerobic exercise capacity impairment has been reported in adults and adolescents following HIV infection. ${ }^{89}$ Ong et $a l^{10}$ have recently shown that, 3 months after hospital discharge, $41 \%$ of adult SARS survivors had reduced aerobic capacity that could not be adequately explained solely by impaired pulmonary function. They suggested that the reduced exercise capacity was probably related to myopathy or physical deconditioning. Whether children affected by SARS have similar a sequel and its progress with time has not been reported. This study aimed to assess the aerobic capacity and pulmonary function of children 6 and 15 months after an acute episode of SARS.

\section{METHODS}

\section{Subjects}

The patient group comprised children who had previously received hospital treatment for SARS at one of the five participating paediatric centres in Hong Kong who satisfied the following inclusion criteria: (1) serological confirmation of SARS-CoV infection, (2) age less than 18 years at the time of diagnosis, (3) 6 months had elapsed since the diagnosis of SARS was made, and (4) no upper respiratory tract infection symptoms during the 2 weeks before the study. This study was approved by the ethics review board of the Chinese University of Hong Kong. Written consent was obtained from the subjects and their parents.

A control group was drawn from a cohort of 147 healthy children matched for sex, age and height. These children were recruited from 10 randomly chosen government funded schools in Hong Kong to participate in a separate study, ${ }^{11}$ and written parental and child consent were obtained.

\footnotetext{
Abbreviations: $\mathrm{FEV}_{1}$, forced expiratory volume in 1 second; $\mathrm{FEF}_{25-75 \text {, }}$ mid forced expiratory flow; FRC, functional residual capacity; FVC, forced vital capacity; HR, heart rate; OUES, oxygen uptake efficiency slope; $\mathrm{PETO}_{2}$, end tidal oxygen partial pressure; $\mathrm{PETCO}_{2}$, end tidal carbon dioxide partial pressure; PFT, pulmonary function test; RER, respiratory exchange ratio; RR, respiratory rate; TLC, total lung capacity; TLCO, carbon monoxide transfer factor; VAT, ventilatory anaerobic threshold; $\mathrm{VE}$, minute ventilation; $\mathrm{VO}_{2}$, oxygen consumption; $\mathrm{VE}_{\mathrm{E}} / \mathrm{VO}_{2}$, ventilatory equivalent for oxygen; $\mathrm{VE} / \mathrm{VCO}_{2}$, ventilatory equivalent for carbon dioxide
} 


\section{Assessments of children in patient group}

Eligible subjects were invited to undergo assessment at 6 and 15 months after the diagnosis of SARS was made. During the visit the subjects were interviewed and underwent a physical examination. Their body mass was measured using an electronic body weight scale (Seca Delta Model 707) and their height was measured with a Harpenden stadiometer. All subjects then underwent pulmonary function tests (PFTs), high resolution computed tomography of the thorax (HRCT), and a maximal treadmill exercise test. The methodological details of the PFTs and HRCT have been described elsewhere. ${ }^{7}$ In brief, PFTs were carried out according to the recommended standard. ${ }^{12}$ Forced expiratory volume in 1 second $\left(\mathrm{FEV}_{1}\right)$ and forced vital capacity (FVC) were measured using spirometry (Medical Graphics Pulmonary Function System with BreezeSuite Software, Medical Graphics Corporation, St Paul, MN, USA), total lung capacity (TLC) was measured by body plethysmography (MedGraphics elite Series Plethysmography) and lung transfer factor (TLCo) by the single breath carbon monoxide technique. The PFT results were expressed as percentages of predicted normal values using local references. ${ }^{13}$

HRCT scans were assessed using a multidetector scanner (LightSpeed 16; GE Medical Systems, Milwaukee, USA). During this procedure, subjects were in a supine position and performed breath holding at full inspiration and at maximal expiration. All images were reviewed by a paediatric radiologist for the presence and distribution of residual radiological abnormalities. The radiologist was blinded to the clinical information and pulmonary status of the subjects.

Fifteen months after the diagnosis of SARS, all subjects who had successfully completed the maximal exercise test at 6 months were invited to return for repeat assessments. Only those with abnormal HRCT scans at 6 months underwent repeat scanning at 15 months.

\section{Maximal treadmill exercise test}

The testing procedure was explained after arrival at the exercise laboratory. Subjects were then given time to practice on the treadmill before the formal exercise test. Aerobic capacity was assessed using an electromechanical treadmill (GE Marquette Medical Systems with centre ETT system, Advanced BioSystems, FL, USA) which was programmed according to the Bruce protocol. ${ }^{14}$ After a steady resting period, subjects were asked to walk on the treadmill at a speed of $1.7 \mathrm{mph}$ and a gradient of $10 \%$ for 3 minutes. The speed and grade were then increased by $0.8 \mathrm{mph}$ and $2 \%$ respectively every 3 minutes until the treadmill reached $5 \mathrm{mph}$ and $18 \%$ gradient. After this the speed was increased by $0.5 \mathrm{mph}$ every 3 minutes. Breath by breath gas samples were collected using a comfortably fitted facemask (Hans Rudolph paediatric large size, 8950 series) and analysed throughout the test by open circuit calorimetry using the Medgraphics System CPX/D metabolic cart (Medical Graphics Corporation, St Paul, MN, USA). Care was taken to ensure complete safety and a physician was present during the whole procedure. The heart rate was monitored continuously during the test. A maximum effort during the test was assumed when two of the following three conditions were reached: (1) respiratory exchange ratio (RER) $>1.0$; (2) heart rate $>95 \%$ of predicted maximum; ${ }^{15} 16$ (3) clear signs of exhaustion (facial flushing, unsteady gait) and refusal to carry on despite strong verbal encouragement.

Gas exchange data at peak exercise were recorded. Submaximal responses including the ventilatory anaerobic threshold (VAT) and the oxygen uptake efficiency slope (OUES) were also documented. VAT was defined as the level of oxygen consumption $\left(\mathrm{VO}_{2}\right)$ at which one of the following diagnostic criteria had been satisfied: (1) an increase in ventilatory equivalent for oxygen $\left(\mathrm{VE} / \mathrm{VO}_{2}\right)$ without a simultaneous decrease in ventilatory equivalent for carbon dioxide $\left(\mathrm{VE} / \mathrm{VCO}_{2}\right) ;$ (2) an increase in end tidal oxygen partial pressure $\left(\mathrm{PETO}_{2}\right)$ without a simultaneous decrease in end tidal carbon dioxide partial pressure $\left(\mathrm{PeTCO}_{2}\right)$; and (3) the Vslope method ${ }^{17}$ The OUES represented the rate of increase in $\mathrm{VO}_{2}$ in response to minute ventilation $(\mathrm{VE})$ and is described by the following exponential function:

$\mathrm{VO}_{2}=a \times \log \mathrm{VE}+\mathrm{b}$

where $a$ represents the rate of increase in $\mathrm{VO}_{2}$ in response to $\mathrm{VE}$ and $\mathrm{b}$ is a constant. ${ }^{18}$

The OUES and maximal exercise responses of the control healthy children were used for comparison.

\section{Statistical analysis}

Anthropometric measurements of the subjects and normal controls were compared using the Student's $t$ test. A generalised linear model (GLM) was performed to compare pulmonary function outcomes and exercise responses 6 months after the diagnosis of SARS between the subjects and controls adjusted for the $\mathrm{z}$ score of weight for age. Pearson correlation coefficients were used to determine an association between subjects' resting lung function and the endurance parameters, and to assess the association between the $\mathrm{z}$ score of weight for age and the change in exercise responses between 6 and 15 months from the diagnosis of SARS. Analysis of covariance (ANCOVA) was used to compare the change in exercise responses over the two time periods for the subgroups, which were classified according to their HRCT results. Paired $t$ tests were used to compare the exercise responses within the subgroups. The $\chi^{2}$ test was performed to compare the recorded symptoms at the end of the exercise test. All statistical analyses were carried out using SPSS for Windows Release 13.0 (SPSS Inc, Chicago, IL, USA) and the level of significance was set at $5 \%$.

\section{RESULTS}

Forty seven patients (45\% female) were recruited and participated in the assessment at 6 months. None of the patients required readmission following discharge from hospital. They were all clinically asymptomatic and had normal clinical examination. Two patients suffered from allergic rhinitis for which they received antihistamine as required. Three patients suffered from asthma; two were receiving low dose inhaled corticosteroids and the other was using an inhaled bronchodilator as required. The clinical presentation, course of recovery, and treatment of this cohort of patients have been reported elsewhere. ${ }^{7}$ Eight of the patients were too young to perform the peak $\mathrm{VO}_{2}$ running test and five did not satisfy the criteria for a maximal effort. The mean (SE) age of the remaining 34 patients was 14.7 (0.4) years. Five of them required oxygen supplementation and two required mechanical ventilation during the acute illness. Data from the 34 patients and 34 controls matched for race, age, sex, and height were compared. The physical characteristics of the two groups were similar (table 1).

Table 1 Mean (SE) characteristics of study subjects

\begin{tabular}{llll}
\hline & SARS patients & Controls & p value* \\
\hline Sex (M:F) & $21: 13$ & $21: 13$ & 1.000 \\
Age (years) & $14.7(0.4)$ & $14.0(0.3)$ & 0.193 \\
Height $(\mathrm{cm})$ & $160.3(2.2)$ & $160.0(2.2)$ & 0.934 \\
Weight $(\mathrm{kg})$ & $55.1(2.2)$ & $51.6(2.2)$ & 0.263 \\
$\mathrm{BMI}\left(\mathrm{kg} / \mathrm{m}^{2}\right)$ & $21.3(0.6)$ & $19.9(0.7)$ & 0.143 \\
\hline \multirow{4}{*}{$p$ values determined by Student's $t$ test except for sex which was } \\
determined by the $\chi^{2}$ test.
\end{tabular}


Table 2 Maximal and submaximal exercise responses 6 months after SARS diagnosis

\begin{tabular}{|c|c|c|c|c|}
\hline & \multicolumn{2}{|c|}{ Adjusted mean (SE)* } & \multirow[b]{2}{*}{$\begin{array}{l}\text { Adjusted mean difference } \\
(95 \% \mathrm{Cl})\end{array}$} & \multirow[b]{2}{*}{ p value } \\
\hline & $\begin{array}{l}\text { Patients } \\
(n=34)\end{array}$ & $\begin{array}{l}\text { Controls } \\
(n=34)\end{array}$ & & \\
\hline $\begin{array}{l}\text { Peak } \mathrm{VO}_{2}(\mathrm{ml} / \mathrm{min}) \\
\text { Peak } \mathrm{VO}_{2}(\mathrm{ml} / \mathrm{kg} / \mathrm{min}) \\
\text { Peak RER } \\
\text { Peak heart rate (beats/min) } \\
\text { Peak } \mathrm{O}_{2} \text { pulse (ml/beat) } \\
\text { Peak respiratory rate (breaths } / \mathrm{min}) \\
\text { Peak } \mathrm{VE}(\mathrm{l} / \mathrm{min}) \\
\text { Peak } \mathrm{VE} / \mathrm{VO}_{2} \\
\text { OUES }\end{array}$ & $\begin{array}{l}1479.5(102.6) \\
27.4(1.3) \\
1.2(0.01) \\
192.9(1.3) \\
7.7(0.5) \\
51.0(1.8) \\
67.9(2.9) \\
49.1(1.4) \\
634.8(45.5)\end{array}$ & $\begin{array}{l}2194.8(102.6) \\
42.3(1.3) \\
1.1(0.01) \\
199.9(1.3) \\
11.2(0.6) \\
52.8(1.8) \\
75.9(2.9) \\
35.0(1.4) \\
1068.4(47.4)\end{array}$ & $\begin{array}{l}-715.3(-1006.4 \text { to }-424.2) \\
-14.8(-18.6 \text { to }-11.0) \\
0.09(0.05 \text { to } 0.13) \\
-6.9(-10.5 \text { to }-3.4) \\
-3.4(-5.0 \text { to }-1.9) \\
-1.8(-6.8 \text { to } 3.2) \\
-8.0(-16.3 \text { to } 0.3) \\
14.2(10.1 \text { to } 18.2) \\
-433.6(-565.4 \text { to }-301.8)\end{array}$ & $\begin{array}{l}<0.0005 \\
<0.0005 \\
<0.0005 \\
<0.0005 \\
<0.0005 \\
0.474 \\
0.059 \\
<0.0005 \\
<0.0005\end{array}$ \\
\hline
\end{tabular}

$\mathrm{VO}_{2}$, oxygen consumption; $\mathrm{VE}$, minute ventilation; RER, respiratory exchange ratio; OUES, oxygen uptake efficiency slope.

Values are adjusted for the $\mathrm{z}$ score of weight for age.

Maximal and submaximal exercise responses of the patient and control groups are shown in table 2. At 6 months the patient group had absolute and mass related peak $\mathrm{VO}_{2}$ values $32.5 \%$ and $34.9 \%$ lower than the control group, respectively $(\mathrm{p}<0.05)$. When compared with Armstrong and Welsman's age and sex predicted values, ${ }^{19}$ the control group recorded values of 91\% predicted (predicted peak $\mathrm{VO}_{2} 2360$ (480) ml/ min), similar to previous findings for 13-16 year old Hong Kong Chinese youngsters, ${ }^{11}$ while the patients only achieved values of $61 \%$ predicted (predicted peak $\mathrm{VO}_{2} 2460$ (610) ml/ min). Ve was $10.5 \%$ lower, although this difference was not statistically significant, while $\mathrm{VE} / \mathrm{VO}_{2}$ was $40.6 \%$ higher in the patients $(\mathrm{p}<0.05)$. The patient group also had a significantly lower $(3 \%)$ peak heart rate and $30.4 \%$ lower peak $\mathrm{O}_{2}$ pulse $(p<0.05)$ than the controls. There was, however, no significant difference in absolute and mass related peak $\mathrm{VO}_{2}$ between patients who required oxygen supplementation/ mechanical ventilation and those who did not. The submaximal exercise response as reflected by the OUES was $40.6 \%$ lower in the patient group than in the controls $(\mathrm{p}<0.05)$.

Pulmonary function testing at 6 months showed a restrictive deficit in two subjects and an obstructive deficit in one. All abnormalities were mild ( $>70 \%$ predicted). There was therefore discordance in impairment between the exercise capacity and pulmonary function of our subjects. HRCT scanning showed that residual ground glass opacification was present in five subjects, air trapping in six, and a combination of the two in three. There were no significant differences in physical characteristics, the use of medications including systemic corticosteroids during hospitalisation, length of hospital stay, and lung function parameters between those with normal and those with abnormal HRCT scans. A significant association was observed between functional residual capacity (FRC) by plethysmography and
TLCO $(r=0.552, \mathrm{p}=0.001)$ and peak $\mathrm{VO}_{2} \quad(r=0.493$, $\mathrm{p}=0.003)$. The pulmonary function parameters of patients with normal and abnormal HRCT scans are shown in table 3.

The exercise responses of the subjects by normal and abnormal HRCT findings are summarised in table 4. Subjects with abnormal HRCT scans had a $24.6 \%$ lower mass related peak $\mathrm{VO}_{2}(\mathrm{p}=0.008)$ and a higher peak $\mathrm{VE} / \mathrm{VO}_{2}(\mathrm{p}=0.049)$ than those with normal HRCT scans.

Seven of the 34 subjects for whom exercise data were available at 6 months did not return for reassessment at 15 months. The rest had normal pulmonary function at 15 months. There was no association between the $\mathrm{z}$ score of weight for age and the change in exercise responses between 6 and 15 months. The absolute and mass related peak $\mathrm{VO}_{2}$ increased at 15 months but still remained suboptimal compared with normal controls (table 5). The respiratory rate, $\mathrm{VE}, \mathrm{VE} / \mathrm{VO}_{2}$ and $\mathrm{VE} / \mathrm{VCO}_{2}$ of the patients decreased significantly $(\mathrm{p}<0.05)$ while $\mathrm{PETO}_{2}$ and $\mathrm{PETCO}_{2}$ - increased. In addition, oxygen pulse at peak exercise and the OUES increased significantly at 15 months compared with the values at 6 months.

Of the initial 14 subjects with abnormal HRCT scans at 6 months, two did not return for rescanning. The HRCT findings did not show significant interval changes for the remaining 12 patients. The exercise responses of the subjects with normal and abnormal HRCT scans are shown in table 6. ANCOVA did not show significant differences in the change in exercise responses in the two subgroups over the 9 month period. Within group comparisons showed that both subgroups had significant improvements in $\mathrm{VE} / \mathrm{VO}_{2}$ (difference (95\% CI) between normal and abnormal HRCT results -9.9 $(-16.2$ to -3.7$)$ and $-13.6(-19.5$ to -7.7$), p=0.004$ and $\mathrm{p}<0.0005$, respectively), $\mathrm{VE} / \mathrm{VCO}_{2}(-8.8(-14.0$ to -3.6$)$ and $-11.3(-16.4$ to -6.1$), \mathrm{p}=0.003$ and $\mathrm{p}=0.001), \mathrm{PeTO}_{2}(12.9$

Table 3 Pulmonary function tests in patients by HRCT findings 6 months after SARS diagnosis

\begin{tabular}{|c|c|c|c|c|}
\hline & \multicolumn{2}{|l|}{ Adjusted mean (SE)* } & \multirow[b]{2}{*}{$\begin{array}{l}\text { Adjusted mean difference } \\
(95 \% \mathrm{CI})\end{array}$} & \multirow[b]{2}{*}{ p value } \\
\hline & $\begin{array}{l}\text { Normal HRCT scan } \\
(\mathrm{n}=20)\end{array}$ & $\begin{array}{l}\text { Abnormal HRCT scan } \\
(n=14)\end{array}$ & & \\
\hline FVC (\% predicted) & $93.6(2.7)$ & $89.6(3.1)$ & $-3.9(-12.3$ to 4.5$)$ & 0.348 \\
\hline $\mathrm{FEV}_{1}(\%$ predicted) & $90.0(2.3)$ & $86.4(2.7)$ & $-3.7(-10.8$ to 3.5$)$ & 0.309 \\
\hline $\mathrm{FEV}_{1} / \mathrm{FVC}$ (\% predicted) & $96.5(2.1)$ & $97.8(2.5)$ & $1.3(-5.3$ to 7.9$)$ & 0.687 \\
\hline $\mathrm{FEF}_{25-75}(\%$ predicted) & $87.6(5.3)$ & $86.6(6.2)$ & $-1.0(-17.8$ to 15.7$)$ & 0.900 \\
\hline TLC (\% predicted) & $100.5(3.7)$ & $101.3(4.2)$ & $0.8(-10.7$ to 12.2$)$ & 0.893 \\
\hline FRC (pleth) (l) & $2.2(0.1)$ & $2.1(0.2)$ & $-0.1(-0.6$ to 0.3$)$ & 0.512 \\
\hline $\mathrm{TLCO}(\mathrm{ml} / \mathrm{min} / \mathrm{mm} \mathrm{Hg})$ & $23.6(2.0)$ & $21.2(2.2)$ & $-2.4(-8.6$ to 3.8$)$ & 0.431 \\
\hline TLCO (\% predicted) & $116.6(7.5)$ & $107.0(8.2)$ & $-9.6(-32.3$ to 13.1$)$ & 0.397 \\
\hline
\end{tabular}

$\mathrm{FEV}_{1}$, forced expiratory volume in 1 second; FVC, forced vital capacity; FRC, functional residual capacity; $\mathrm{FEF}_{25-75}$, mid forced expiratory flow; TLC, total lung capacity; TLCO, carbon monoxide transfer factor.

*Values are adjusted for the $\mathrm{z}$ score of weight for age. 
Table 4 Maximal and submaximal exercise responses in patients by HRCT findings 6 months after SARS diagnosis

\begin{tabular}{|c|c|c|c|c|}
\hline & \multicolumn{2}{|l|}{ Adjusted mean (SE)* } & \multirow[b]{2}{*}{$\begin{array}{l}\text { Adjusted mean difference } \\
(95 \% \mathrm{Cl})\end{array}$} & \multirow[b]{2}{*}{ p value } \\
\hline & $\begin{array}{l}\text { Normal HRCT scan } \\
(n=20)\end{array}$ & $\begin{array}{l}\text { Abnormal HRCT scan } \\
(n=14)\end{array}$ & & \\
\hline Resting $\mathrm{VO}_{2}(\mathrm{ml} / \mathrm{min})$ & $229.3(13.3)$ & $201.6(15.9)$ & $-27.8(-70.3$ to 14.8$)$ & 0.193 \\
\hline Respiratory quotient & $0.87(0.02)$ & $0.86(0.02)$ & $-0.01(-0.06$ to 0.04$)$ & 0.752 \\
\hline Resting HR (beats/min) & $88.3(3.3)$ & $86.7(3.9)$ & $-1.6(-12.1$ to 8.9$)$ & 0.753 \\
\hline Resting RR (breaths/min) & $18.8(1.0)$ & $19.7(1.2)$ & $0.9(-2.4$ to 4.2$)$ & 0.572 \\
\hline Resting VE (l/min) & $9.1(0.4)$ & $8.8(0.5)$ & $-0.3(-1.6$ to 1.0$)$ & 0.620 \\
\hline Peak $\mathrm{VO}_{2}(\mathrm{ml} / \mathrm{min})$ & 1668.9 (131.9) & $1294.0(158.1)$ & $-374.9(-797.8$ to 48.1$)$ & 0.080 \\
\hline Peak $\mathrm{VO}_{2}(\mathrm{ml} / \mathrm{kg} / \mathrm{min})$ & $30.5(1.7)$ & $23.0(2.0)$ & $-7.5(-12.9$ to -2.1$)$ & 0.008 \\
\hline Peak RER & $1.2(0.02)$ & $1.2(0.02)$ & $0.04(-0.02$ to 0.10$)$ & 0.153 \\
\hline Peak HR (beats/min) & $193.4(2.0)$ & $192.7(2.4)$ & $-0.7(-7.1$ to 5.7$)$ & 0.823 \\
\hline Peak $\mathrm{O}_{2}$ pulse (ml/beat) & $8.7(0.7)$ & $6.7(0.9)$ & $-2.1(-4.4$ to 0.3$)$ & 0.080 \\
\hline Peak RR (breaths/min) & $50.5(2.4)$ & $51.6(2.9)$ & $1.1(-6.6$ to 8.8$)$ & 0.689 \\
\hline Peak VE (I/min) & $71.8(3.6)$ & $65.2(4.3)$ & $-6.6(-18.0$ to 4.9$)$ & 0.250 \\
\hline Peak $\mathrm{VE} / \mathrm{VO}_{2}$ & $45.8(2.4)$ & $53.5(2.8)$ & $7.7(0.1$ to 15.3$)$ & 0.049 \\
\hline Peak $\mathrm{VE} / \mathrm{VCO}_{2}$ & $40.0(2.0)$ & $44.4(2.4)$ & $4.4(-2.0$ to 10.7$)$ & 0.172 \\
\hline $\mathrm{PETO}_{2}(\mathrm{~mm} \mathrm{Hg})$ & $93.0(3.6)$ & $91.0(4.3)$ & $-2.1(-13.5$ to 9.3$)$ & 0.714 \\
\hline $\mathrm{PETCO}_{2}(\mathrm{~mm} \mathrm{Hg})$ & $32.5(1.7)$ & $29.4(2.0)$ & $-3.0(-8.3$ to 2.2$)$ & 0.248 \\
\hline VAT $(\mathrm{ml} / \mathrm{min})$ & $979.4(78.7)$ & $793.3(94.4)$ & $-186.1(-438.5$ to 66.3$)$ & 0.143 \\
\hline OUES & $712.7(62.6)$ & $562.9(71.9)$ & $-149.8(-344.9$ to 45.3$)$ & 0.128 \\
\hline Exercise time (s) & $602.2(48.0)$ & $569.2(61.9)$ & $-33.0(-194.0$ to 127.9$)$ & 0.679 \\
\hline \multicolumn{5}{|c|}{$\begin{array}{l}\mathrm{VO}_{2} \text {, oxygen consumption; } \mathrm{VE} \text {, minute ventilation; } \mathrm{HR} \text {, heart rate; } \mathrm{RER} \text {, respiratory exchange ratio; } \mathrm{RR} \text {, respiratory rate; } \mathrm{VE}^{\mathrm{V}} / \mathrm{VO}_{2}, \mathrm{VE} / \mathrm{V} \mathrm{CO}_{2}, \text { ventilatory equivalent } \\
\text { for oxygen and carbon dioxide; } \mathrm{PETO}_{2}, \mathrm{PETCO}_{2} \text {, end tidal oxygen and carbon dioxide partial pressures; VAT, ventilatory anaerobic threshold; OUES, oxygen } \\
\text { uptake efficiency slope. } \\
\text { *Values are adjusted for the } z \text { score of weight for age. }\end{array}$} \\
\hline
\end{tabular}

(2.3 to 23.6) and 24.6 (14.0 to 35.2$) \mathrm{mm} \mathrm{Hg}, \mathrm{p}=0.021$ and $\mathrm{p}<0.0005)$ and $\mathrm{PeTCO}_{2}(6.5(2.5$ to 10.5$)$ and 8.8 (5.1 to 12.6) $\mathrm{mm} \mathrm{Hg}, \mathrm{p}=0.004$ and $\mathrm{p}<0.0005$ ) at peak exercise at 15 months. Those with abnormal HRCT scans also showed significant improvements in absolute peak $\mathrm{VO}_{2}$ (difference (95\% CI) 296.8 ( 112.8 to 480.9 ) $\mathrm{ml} / \mathrm{min}, \mathrm{p}=0.005$ ) and mass related peak $\mathrm{VO}_{2}(4.6$ ( 1.2 to 7.9$\left.) \mathrm{ml} / \mathrm{kg} / \mathrm{min}, \mathrm{p}=0.012\right)$, peak oxygen pulse (1.7 (0.7 to 2.6$) \mathrm{ml} /$ beat, $\mathrm{p}=0.002)$, peak respiratory rate $(-5.9(-11.2$ to -0.7$)$ breaths $/ \mathrm{min}$, $\mathrm{p}=0.031)$, VAT $(181.3(67.1$ to 295.6$) \mathrm{ml} / \mathrm{min}, \mathrm{p}=0.005)$, and OUES (112.3 (13.2 to 211.4), $\mathrm{p}=0.030)$ at 15 months compared with values at 6 months.

At 6 months after diagnosis $85 \%$ of the patients with normal HRCT scans reported leg fatigue and $10 \%$ reported breathlessness as the reason for terminating the exercise test.
For those with abnormal HRCT scans, $84.6 \%$ reported leg fatigue and $7 \%$ reported breathlessness as their reason for test termination $(\mathrm{p}=0.525)$. At 15 months after diagnosis 91\% of the patients with normal HRCT scans reported leg fatigue but none gave breathlessness as their reason for terminating the exercise test; the corresponding figures for the those with abnormal HRCT scans were $90 \%$ and $10 \%$, respectively $(\mathrm{p}=0.366)$.

\section{DISCUSSION}

Studies examining the sequelae of SARS are limited and most have concentrated on the early phases of rehabilitation (16 months). ${ }^{3102021}$ To the best of our knowledge, this is the first study to examine later stage recovery in children and adolescents who contracted the SARS CoV. The main

Table 5 Mean (SE) physical characteristics and exercise responses of 27 patients 6 and 15 months after SARS diagnosis

\begin{tabular}{|c|c|c|c|c|}
\hline & 6 months & 15 months & Difference $(95 \% \mathrm{Cl})$ & p value* \\
\hline Height $(\mathrm{cm})$ & $160.6(2.5)$ & $162.3(2.4)$ & $1.7(1.0$ to 2.4$)$ & $<0.0005$ \\
\hline Weight (kg) & $56.7(2.6)$ & $58.3(2.6)$ & $1.6(0.4$ to 2.8$)$ & 0.008 \\
\hline BMI $\left(\mathrm{kg} / \mathrm{m}^{2}\right)$ & $21.8(0.7)$ & $22.0(0.8)$ & $0.2(-0.2$ to 0.6$)$ & 0.313 \\
\hline Resting $\mathrm{Vo}_{2}(\mathrm{ml} / \mathrm{min})$ & $228.3(11.3)$ & $233.6(14.9)$ & $5.3(-22.8$ to 33.4$)$ & 0.702 \\
\hline Respiratory quotient & $0.86(0.01)$ & $0.83(0.02)$ & $-0.03(-0.06$ to 0.00$)$ & 0.062 \\
\hline Resting HR (beats/min) & $87.3(2.4)$ & $81.5(2.7)$ & $-5.8(-11.0$ to -0.6$)$ & 0.032 \\
\hline Resting RR (breaths/min) & $19.7(0.9)$ & $19.1(0.9)$ & $-0.63(-2.1$ to 0.8$)$ & 0.376 \\
\hline Resting VE (I/min) & $9.1(0.3)$ & $8.3(0.4)$ & $-0.9(-1.76$ to 0.02$)$ & 0.058 \\
\hline Peak $\mathrm{VO}_{2}(\mathrm{ml} / \mathrm{min})$ & $1595.6(127.5)$ & $1780.4(95.6)$ & $112.8(-60.4$ to 286.0$)$ & 0.192 \\
\hline Peak $\mathrm{VO}_{2}(\mathrm{ml} / \mathrm{kg} / \mathrm{min})$ & $28.0(1.7)$ & $29.6(1.2)$ & $1.6(-1.6$ to 4.8$)$ & 0.306 \\
\hline Peak RER & $1.2(0.0)$ & $1.2(0.0)$ & $0.00(-0.04$ to 0.05$)$ & 0.861 \\
\hline Peak HR (beats/min) & $192.8(1.7)$ & $190.8(1.6)$ & $-2.0(-4.9$ to 0.8$)$ & 0.153 \\
\hline Peak $\mathrm{O}_{2}$ pulse $(\mathrm{ml} /$ beat) & $8.3(0.7)$ & $8.9(0.5)$ & $0.6(-0.4$ to 1.6$)$ & 0.217 \\
\hline Peak RR (breaths/min) & $51.0(2.2)$ & $46.6(2.0)$ & $-4.4(-8.1$ to -0.7$)$ & 0.022 \\
\hline Peak Ve (I/min) & $70.5(3.4)$ & $61.3(3.7)$ & $-9.1(-16.5$ to -1.8$)$ & 0.017 \\
\hline Peak VE/ $/ \mathrm{VO}_{2}(\mathrm{~mm} \mathrm{Hg})$ & $47.8(2.3)$ & $36.2(1.0)$ & $-11.6(-15.7$ to -7.4$)$ & $<0.0005$ \\
\hline Peak $\mathrm{VE} / \mathrm{VCO}_{2}(\mathrm{~mm} \mathrm{Hg})$ & $39.8(2.0)$ & $30.0(0.8)$ & $-9.9(-13.3$ to -6.4$)$ & $<0.0005$ \\
\hline $\mathrm{PETO}_{2}(\mathrm{~mm} \mathrm{Hg})$ & $95.2(3.1)$ & $113.3(0.9)$ & $18.1(10.7$ to 25.5$)$ & $<0.0005$ \\
\hline $\mathrm{PETCO}_{2}(\mathrm{~mm} \mathrm{Hg})$ & $32.7(1.7)$ & $40.2(1.0)$ & $7.5(4.9$ to 10.1$)$ & $<0.0005$ \\
\hline VAT $(\mathrm{ml} / \mathrm{min})$ & $964.5(77.9)$ & $1028.4(54.4)$ & $63.9(-62.5$ to 190.2$)$ & 0.308 \\
\hline OUES & $711.1(66.8)$ & $822.5(42.1)$ & $111.4(16.6$ to 206.1$)$ & 0.023 \\
\hline Exercise time (s) & $626.7(24.1)$ & $557.9(17.6)$ & $-68.8(-111.8$ to -25.7$)$ & 0.003 \\
\hline
\end{tabular}

$\mathrm{VO}_{2}$, oxygen consumption; $\mathrm{VE}$, minute ventilation; $\mathrm{HR}$, heart rate; $\mathrm{RER}$, respiratory exchange ratio; RR, respiratory rate; $\mathrm{O}_{2}$ pulse, oxygen consumption per heart beat; $\mathrm{VE} / \mathrm{VO}_{2}, \mathrm{VE} / \mathrm{VCO}_{2}$, ventilatory equivalent for oxygen and carbon dioxide; $\mathrm{PETO}, \mathrm{PETCO}_{2}$, end tidal oxygen and carbon dioxide partial pressures; $\mathrm{VAT}$, ventilatory anaerobic threshold; OUES, oxygen uptake efficiency slope.

*Paired $t$ test. 
Table 6 Physical characteristics and exercise responses by HRCT findings 15 months after SARS diagnosis

\begin{tabular}{|c|c|c|c|c|}
\hline & \multicolumn{2}{|l|}{ Adjusted mean (SE)* } & \multirow[b]{2}{*}{$\begin{array}{l}\text { *Adjusted mean difference } \\
(95 \% \mathrm{Cl})\end{array}$} & \multirow[b]{2}{*}{$p$ value } \\
\hline & $\begin{array}{l}\text { Normal HRCT scan } \\
(n=15)\end{array}$ & $\begin{array}{l}\text { Abnormal HRCT scan } \\
(\mathrm{n}=12)\end{array}$ & & \\
\hline Resting $\mathrm{VO}_{2}(\mathrm{ml} / \mathrm{min})$ & 224.4 (17.9) & $243.6(18.6)$ & $19.2(-35.5$ to 73.8$)$ & 0.476 \\
\hline Respiratory quotient & $0.83(0.02)$ & $0.84(0.02)$ & $0.01(-0.05$ to 0.07$)$ & 0.671 \\
\hline Resting HR (beats/min) & $82.8(3.0)$ & $80.1(3.1)$ & $-2.7(-11.7$ to 6.3$)$ & 0.542 \\
\hline Resting RR (breaths/min) & $19.7(0.9)$ & $18.4(0.9)$ & $-1.3(-4.1$ to 1.4$)$ & 0.325 \\
\hline Resting VE (I/min) & $8.3(0.5)$ & $8.2(0.6)$ & $-0.1(-1.8$ to 1.5$)$ & 0.863 \\
\hline Peak $\mathrm{VO}_{2}(\mathrm{ml} / \mathrm{min})$ & $1665.8(88.7)$ & $1754.2(92.3)$ & $88.5(-186.3$ to 363.2$)$ & 0.512 \\
\hline Peak $\mathrm{VO}_{2}(\mathrm{ml} / \mathrm{kg} / \mathrm{min})$ & $30.1(1.6)$ & $29.0(1.7)$ & $-1.1(-6.3$ to 4.1$)$ & 0.664 \\
\hline Peak RER & $1.2(0.03)$ & $1.2(0.03)$ & $0.03(-0.06$ to 0.12$)$ & 0.473 \\
\hline Peak HR (beats/min) & $192.0(1.8)$ & $189.5(1.8)$ & $-2.5(-7.9$ to 2.8$)$ & 0.334 \\
\hline Peak $\mathrm{O}_{2}$ pulse (ml/beat) & $8.7(0.4)$ & $9.2(0.4)$ & $0.5(-0.8$ to 1.8$)$ & 0.469 \\
\hline Peak RR (breaths/min) & $48.4(2.3)$ & $44.6(2.3)$ & $-3.8(-10.6$ to 3.0$)$ & 0.256 \\
\hline Peak VE (I/min) & $61.0(4.8)$ & $61.7(5.0)$ & $0.6(-13.9$ to 15.1$)$ & 0.928 \\
\hline Peak VE $/ \mathrm{VO}_{2}$ & $36.1(1.3)$ & $36.3(1.3)$ & $0.2(-3.8$ to 4.3$)$ & 0.902 \\
\hline Peak VE/ $/ \mathrm{VCO}_{2}$ & $31.1(0.9)$ & $29.5(1.0)$ & $-1.6(-4.3$ to 1.1$)$ & 0.236 \\
\hline $\mathrm{PETO}_{2}(\mathrm{~mm} \mathrm{Hg})$ & $113.3(0.9)$ & $113.3(1.0)$ & $0.02(-2.9$ to 2.9$)$ & 0.991 \\
\hline $\mathrm{PETCO}_{2}(\mathrm{~mm} \mathrm{Hg})$ & $39.5(1.0)$ & $40.7(1.1)$ & $1.2(-1.9$ to 4.3$)$ & 0.431 \\
\hline VAT $(\mathrm{ml} / \mathrm{min})$ & $1033.1(56.0)$ & $1023.7(56.0)$ & $-9.4(-181.1$ to 162.3$)$ & 0.911 \\
\hline OUES & $775.6(40.4)$ & $820.9(43.5)$ & $45.3(-79.1$ to 169.7$)$ & 0.460 \\
\hline Exercise time (s) & $589.2(20.8)$ & $524.1(21.6)$ & $-65.1(-128.9$ to -1.2$)$ & 0.046 \\
\hline
\end{tabular}

*Values are adjusted for the $\mathrm{z}$ score of weight for age and at 6 months.

$\mathrm{VO}_{2}$, oxygen consumption; $\mathrm{VE}$, minute ventilation; $\mathrm{HR}$, heart rate; $\mathrm{RER}$, respiratory exchange ratio; $\mathrm{RR}$, respiratory rate; $\mathrm{O}_{2}$ pulse, oxygen consumption per heart beat; $\mathrm{VE} / \mathrm{VO}_{2}, \mathrm{VE} / \mathrm{VCO}_{2}$, ventilatory equivalent for oxygen and carbon dioxide; $\mathrm{PETO}_{2}, \mathrm{PETCO}{ }_{2}$, end tidal oxygen and carbon dioxide partial pressures; $\mathrm{VAT}$, ventilatory anaerobic threshold; OUES, oxygen uptake efficiency slope.

findings of the current study were: (1) impairment of aerobic capacity in asymptomatic children at 6 months which persisted to 15 months after the diagnosis was made; (2) those with residual radiological abnormalities had a significantly greater reduction in aerobic capacity than those with normal HRCT scans at 6 months but this association no longer existed at 15 months; and (3) the reduction in aerobic capacity appears to be related to impaired lung function but is probably also the result of deconditioning following this acute illness.

Studies investigating aerobic capacity following viral infections are sparse and the few reported studies have focused on patients with HIV. Decreased aerobic capacity has been reported in adults and late adolescents infected with HIV. ${ }^{8}{ }^{22}$ These studies have shown that peak $\mathrm{VO}_{2}$ values were 24-35\% below the expected normal target. Several potential mechanisms-including pulmonary dysfunction, anaemia, cardiovascular dysfunction, peripheral muscle oxygen extraction limitation, and deconditioning — have been proposed for the decreased aerobic capacity in these patients. ${ }^{23}$ In relation to SARS CoV infection, a study that examined laboratory determined aerobic capacity in adult SARS survivors found that $41 \%$ had aerobic capacity values below the lower limit of a reference norm. ${ }^{10}$ This reduction in aerobic capacity, however, could not be accounted for by pulmonary function impairment alone as the lung function abnormalities were mild. The self-paced 6 minute walk test (6MWT) was performed to evaluate the global and integrated responses to exercise in another cohort of adult SARS survivors. ${ }^{21}$ The subjects' performance on the 6MWT was significantly impaired, out of proportion to the degree of lung function abnormality at 6 months following the diagnosis. ${ }^{21}$

Aerobic capacity impairment was found in our cohort of asymptomatic patients at 6 months and persisted to 15 months following the diagnosis of SARS. Similar to the reported literature in adult patients, this reduction in aerobic capacity occurred despite relatively mild pulmonary function abnormalities. At 6 months only three of the 34 patients had abnormal lung function, two with a restrictive deficit and one with an obstructive deficit; these had returned to normal when the test was repeated at 15 months. However, the increased oxygen cost of breathing at maximal exercise noted indicates altered respiratory muscle dynamics. At 6 months the patient group had significantly higher $\mathrm{VE} / \mathrm{VO}_{2}$ than normal controls and, within the patient group, those with residual radiological abnormalities had an increased $\mathrm{VE} / \mathrm{VO}_{2}$. An increase in physiological dead space could explain the abnormal $\mathrm{VE} / \mathrm{VO}_{2}$ seen in our patients as their resting and peak respiratory rates were found to be comparable to those of normal controls. ${ }^{17}$ It is possible that such subtle defective respiratory muscle dynamics may not have been apparent in the static lung function test but became apparent when the patients were subjected to stress.

In the 14 patients with residual radiological abnormalities, the HRCT scan showed ground glass opacification and/or air trapping. The presence of ground glass opacification indicates an increase in the density of soft tissue within the lung, while not completely filling the air spaces. ${ }^{24}$ This abnormality would interfere with normal lung gas exchange, causing reduced lung compliance and thus further increasing the work of breathing. ${ }^{25}$ Air trapping causes a decrease in pulmonary blood flow and leads to gradual atrophy of the involved portion of the lung tissue. ${ }^{26}$ The ventilation of poorly perfused air spaces increases the physiological dead space, thus increasing the ventilatory requirement. ${ }^{25}$ This could explain why patients with residual radiological abnormalities have a higher oxygen cost of breathing at maximal exercise than those with normal radiology.

However, while our data would indicate that the abnormal respiratory muscle dynamics were related to reduced exercise capacity, the absolute peak $\mathrm{VO}_{2}$ remained suboptimal at 15 months despite the fact that the $\mathrm{VE} / \mathrm{VO}_{2}$ had returned to normal.

Oxygen pulse was significantly reduced in the patient group and remained so at 15 months. The oxygen pulse provides a reflection of oxygen taken up by the pulmonary blood during the period of a heart beat, the combined product of stroke volume and the difference between the arterial and mixed venous blood oxygen content. ${ }^{17}$ Assuming stroke volume in our patients remained unaffected on recovery from SARS (as is seen in adult SARS survivors who had a more severe disease course), ${ }^{27}$ it is reasonable to hypothesise 
that the decrease in the peak oxygen pulse can be attributed to the decrease in arteriovenous oxygen difference. This could be explained by the inefficient ventilation at peak exercise as a result of increases in physiological dead space which, in turn, causes a reduction in arterial oxygen tension $\left(\mathrm{PaO}_{2}\right)$ during progressively increasing exercise work rate. ${ }^{17}$ The arteriovenous oxygen difference is dependent on the availability of haemoglobin, blood oxygenation in the lung, and the extraction of oxygen at the periphery. As the patients' haemoglobin levels were within the normal range, ${ }^{28}$ blood oxygenation in the lung and extraction of oxygen at the periphery are two factors that might have contributed to the decrease in arteriovenous oxygen difference at peak exercise.

With regard to blood oxygenation in the lung at peak exercise, increased dead space ventilation was suspected in our group of patients. Since only perfused alveoli can obtain carbon dioxide, underperfused alveoli relative to ventilation would have a low carbon dioxide concentration. ${ }^{17}$ The measurement of $\mathrm{PETCO}_{2}$ ) has been suggested as a reliable non-invasive estimate of $\mathrm{PaCO}_{2} \cdot{ }^{29} \mathrm{PETCO}_{2}$ is the partial pressure of carbon dioxide observed at the end of each exhalation and ideally reflects the alveolar partial pressure of this gas. In our study there was a trend towards decreased $\mathrm{PETCO}_{2}$ in patients with residual radiological abnormalities at 6 months compared with those with normal radiology. Without hyperventilation, as shown by comparable respiratory rates at rest and at peak exercise, a low $\mathrm{PETCO}_{2}$ would reflect a high degree of alveolar ventilation-perfusion ratio mismatching. ${ }^{17}$ PETCO $_{2}$ was significantly higher in all patients at 15 months than at 6 months, indicating an improvement in blood oxygenation in the lungs with time.

Muscle weakness/physical deconditioning could affect peripheral oxygen extraction. Given the fact that the patient group achieved a peak heart rate within the age predicted targets at 6 months, it is unlikely that muscle weakness was a limiting factor for these patients to achieve a maximal exercise effort. ${ }^{30}$ Prolonged confinement and inactivity during and even after the acute stage of illness could lead to clinically significant impaired muscle function. SARS-CoV induced myositis, indicated by raised serum creatine kinase, might also contribute. ${ }^{4-631}$ Steroid induced myopathy has been proposed as a cause of muscular impairment in adult SARS survivors. ${ }^{1021}$ This was less likely to be a major determinant in our group of children as none had received a prolonged course of corticosteroid treatment. Besides patients given higher doses of corticosteroids, those who required oxygen supplementation/mechanical ventilation did not have a greater reduction in aerobic capacity than those with milder disease. There is evidence that the impairment in peak $\mathrm{VO}_{2}$ was reversing in some by 15 months since only $19 \%$ of the patients had peak $\mathrm{VO}_{2}$ values below $25 \mathrm{ml} / \mathrm{kg} / \mathrm{min}$ at 15 months compared with 53\% at 6 months. However, for many, improvement in aerobic capacity to normal levels had not occurred even 15 months after the event.

Physical activity levels of healthy Hong Kong children have been shown to be low, ${ }^{32} 33$ and certainly not of the magnitude necessary to induce improvements in aerobic capacity. Even if these children had resumed their pre-SARS pattern of behaviour, it is likely that this activity pattern is congruent with those of other Hong Kong youngsters and would be insufficient to make any substantial impact on aerobic capacity. There is a growing body of information from animal models to suggest that a range of regulatory factors are altered during periods of confinement and inactivity and reversal probably requires a more rigorous programme of structured exercise. ${ }^{34}$

The measurement of maximal oxygen consumption ( $\left.\mathrm{VO}_{2} \max \right)$ has been widely used as a standard for cardiopulmonary functional reserve. Rather than relying on maximal responses to exercise, valuable information may also be collected from submaximal phases.. ${ }^{35}$ We have evaluated the VAT and OUES for patients as well as healthy control children. VAT is the most frequently used submaximal measurement index and is a gas exchange measurement that can detect the oxygen uptake non-invasively at the onset of lactate acidosis. ${ }^{36}{ }^{37}$ At 6 months there was a trend for VAT to be decreased in patients with abnormal HRCT scans compared with those with normal radiological findings. VAT in patients with abnormal HRCT scans was increased significantly at 15 months compared with the value at 6 months, indicating that the distribution of blood to the working muscle was improving. OUES is a relatively new submaximal index and is calculated from the slope of the logarithmic regression curve expressing the relationship between oxygen uptake and minute ventilation during incremental exercise. The OUES indicates how effectively oxygen is extracted by the lungs and used in the periphery. ${ }^{18}$ The greatest advantage of the OUES is that it is not affected by exercise intensity and appears to be independent of the treadmill protocol. ${ }^{18}{ }^{38}$ In the current study the patient group had a significantly lower OUES than the normal controls at 6 months. The development of metabolic acidosis and increases in physiologic dead space are two factors that can result in the lowering of the OUES. ${ }^{18}{ }^{38}$ During metabolic acidosis, higher mixed venous lactate levels for the same amount of work induce excessive carbon dioxide production which can stimulate ventilation and lead to a lower OUES value. This was an unlikely occurrence in our patients since hyperventilation was not observed during the exercise phases. The lower OUES value in our patients at 6 months was therefore probably influenced by the physiological dead space. Patients with abnormal HRCT scans had a significant increase in OUES at 15 months compared with 6 months, again suggesting improved perfusion to the lungs with time. The submaximal findings are consistent with the conclusions drawn from the maximal responses. Both indicate that the impairment in aerobic capacity in our group of patients is probably related to an increased physiological dead space which results from lung perfusion impairment during exercise.

There are a number of limitations to our study. Firstly, because of the young age of some patients and the inability of others to achieve a maximum effort, only data from 34 of the possible 47 patients were examined. Further analysis showed that the subjects who were not able to perform the exercise test had a clinically milder disease course. It is therefore unlikely that we missed significant lung pathology and radiological abnormalities from those who did not undergo the running exercise test. Secondly, no comprehensive direct assessment of cardiac function was made. It was, however, unlikely that significant cardiac impairment was present as the patients had a normal clinical examination and were able to achieve age predicted maximum heart rates at peak exercise. Finally, because of issues of ethical acceptability related to radiation exposure, we did not subject patients with normal HRCT scans at 6 months to a repeat scan at 15 months. However, we feel that the chance of radiological abnormalities appearing only at 15 months was unlikely.

This study is the most comprehensive report to date of exercise responses following SARS in children and adolescents. Aerobic capacity was impaired at 6 and 15 months after the acute episode of SARS. The mechanism for the reduced aerobic capacity is not fully understood, but it is probably a result of impaired perfusion to the lungs at peak exercise and deconditioning. The time course and/or stimuli necessary to reverse functional impairments following SARS in children are not fully understood. Only thorough continued follow up together with exercise manipulation will we begin to understand whether later improvements are possible for all members of this patient group. 


\section{ACKNOWLEDGEMENTS}

The authors thank Hung K So and Jane Yin for carrying out the lung function and exercise treadmill assessment for this study.

\section{Authors' affiliations}

C C W Yu, A M Li, P C Ng, D Chan, F Cheng, T F Leung, R Y T Sung, T F Fok, Department of Paediatrics, The Chinese University of Hong Kong, Shatin, Hong Kong

R C H So, Sports Institute, Hong Kong Sports Development Board, Hong Kong

C C W Yu, A McManus, Institute of Human Performance, The University of Hong Kong, Hong Kong

W Chu, Department of Diagnostic Radiology and Organ Imaging, The Chinese University of Hong Kong, Shatin, Hong Kong

W K Chiu, Department of Paediatrics and Adolescent Medicine, United Christian Hospital, Hong Kong

C W Leung, Department of Paediatrics and Adolescent Medicine,

Princess Margaret Hospital, Hong Kong

Y S Yau, Department of Paediatrics and Adolescent Medicine, Queen

Elizabeth Hospital, Hong Kong

K W Mo, Department of Paediatrics and Adolescent Medicine, Pamela Youde Nethersole Eastern Hospital, Hong Kong

E M C Wong, A Y K Cheung, Centre for Epidemiology and Biostatistics, Prince of Wales Hospital, The Chinese University of Hong Kong, Shatin, Hong Kong

No special funding.

Competing interests: none declared.

CCWY and AML are joint first authors.

\section{REFERENCES}

1 Kuiken T, Fouchier RA, Schutten M, et al. Newly discovered coronavirus as the primary cause of severe acute respiratory syndrome. Lancet 2003;362:263-70

2 Peiris J, Chu C, Cheng V, et al. Clinical progression and viral load in a community outbreak of coronavirus-associated SARS pneumonia: a prospective study. Lancet 2003;361:1767-72.

3 Chan K, Zheng J, Mok Y, et al. SARS: prognosis, outcome and sequelae. Respirology 2003;8(Suppl):S36-40

4 Hon K, Leung C, Cheng W, et al. Clinical presentations and outcome of severe acute respiratory syndrome in children. Lancet 2003;361:1701-3.

5 Chiu W, Cheung P, Ng K, et al. Severe acute respiratory syndrome in children: experience in a regional hospital in Hong Kong. Pediatr Crit Care Med 2003;4:279-83.

6 Leung $C, K$ wan $Y, K_{0} P$, et al. Severe acute respiratory syndrome among children. Pediatrics 2004; 113:e535-43.

7 Li AM, So H, Chu W, et al. Radiological and pulmonary function outcome of children with SARS. Pediatr Pulmonol 2004;38:427-33.

8 Pothoff G, Wassermann K, Ostmann H. Impairment of exercise capacity in various groups of HIV-infected patients. Respiration 1994;61:80-5.

9 Cade W, Peralta L, Keyser R. Aerobic capacity in late adolescents infected with HIV and controls. Pediatr Rehabil 2002;5:161-9.

10 Ong K, Ng A, Lee L, et al. Pulmonary function and exercise capacity in survivors of severe acute respiratory syndrome. Eur Respir $J$ 2004;24:436-42.

11 McManus AM, Yung T, Leung M. Peak oxygen uptake in relation to age, sex and maturation in Hong Kong Chinese children. Am J Human Biol 2004; 16:602-5.
12 British Thoracic Society. Topical review: guidelines for the measurement of respiratory function. Respir Med 1994;88:165-94.

13 Ip MS, Karlberg EM, Karlberg JP, et al. Lung function reference values in Chinese children and adolescents in Hong Kong. Am J Respir Crit Care Med 2000;162:424-9.

14 Bruce R. Exercise testing of patients with coronary artery disease. Ann Clin Res $1971 ; 3: 323-32$.

15 Armstrong N. Children and aerobic exercise. In: McCracken J, Williams I, eds. Sport, exercise and medicine. Volume 2: Rheumatology, disability and physiology. University of Nottingham, Queen's Medical Centre, 1995:93-116.

16 Rowland TW. Aerobic exercise testing protocols. In: Rowland TW, ed. Pediatric laboratory exercise testing. Champaign, IL: Human Kinetics, 1993:19-41.

17 Wasserman K, Hansen J, Sue D, et al. Principles of exercise testing and interpretation: including pathophysiology and clinical applications, 3rd ed. Philadelphia: Lippincott Williams \& Wilkins, 1999.

18 Baba R, Nagashima M, Goto M, et al. Oxygen uptake efficiency slope: a new index of cardiorespiratory functional reserve derived from the relation between oxygen uptake and minute ventilation during incremental exercise. J Am Coll Cardiol 1996;28:1567-72.

19 Armstrong N, Welsman J. Assessment and interpretation of aerobic fitness in children and adolescents. Exerc Sports Sci Rev 1994;22:435-76.

20 Li A, Chan C, Chan D. Long-term sequelae of SARS in children. Paediatr Respir Rev 2004;5:296-9.

21 Hui DS, Joynt GM, Wong KT, et al. Impact of severe acute respiratory syndrome (SARS) on pulmonary function, functional capacity and quality of life in a cohort of survivors. Thorax 2005:60:401-9.

22 Johnson J, Anders $\mathrm{G}$, Blanton $\mathrm{H}$, et al. Exercise dysfunction in patients seropositive for the human immunodeficiency virus. Am Rev Respir Dis 1990;141:618-22.

23 Stringer W. Mechanisms of exercise limitation in HIV+ individuals. Med Sci Sports Exerc 2000;32(7 Suppl):S412-21.

24 Lucaya J, Le Pointe HD. High-resolution CT of the lung in children. In: Lucaya J, Strife JL, eds. Pediatric chest imaging. Berlin: Springer, 2002:55-91.

25 Hansen JE, Wasserman K. Pathophysiology of activity limitation in patients with interstitial lung disease. Chest 1996;109:1566-76.

26 Kim CK, Chung CY, Kim JS, et al. Late abnormal findings on high-resolution computed tomography after Mycoplasma pneumonia. Pediatrics 2000; 105:372-8.

27 Li S, Cheng C, Fu C, et al. Left ventricular performance in patients with severe acute respiratory syndrome: a 30-day echocardiographic follow-up study. Circulation 2003;108:1798-803.

28 Cheng WT, Li CK, Leung TF, et al. Ribavirin for SARS in children. Clin Pediatr (Phila) 2004;43:193-6.

29 Ohuchi $\mathrm{H}$, Kato $\mathrm{Y}$, Tasato $\mathrm{H}$, et al. Ventilatory response and arterial blood gases during exercise in children. Pediatr Res 1999;45:389-96.

30 De Becker P, Roeykens J, Reynders M, et al. Exercise capacity in chronic fatigue syndrome. Arch Intern Med 2000;160:3270-7.

31 Cheng FWT, Ng PC, Chiu WK, et al. A case-control study of SARS versus community acquired pneumonia. Arch Dis Child 2005:90:745-9.

32 Johns D, Ha A. Home and recess physical activity of Hong Kong children. Res Q Exerc Sport 1999;70:319-23.

33 McManus A, Armstrong N. Physical activity patterns of Hong Kong Chinese primary school children. Pediatr Exerc Sci 1996:8:177-8.

34 Bey L, Akunuri N, Zhao P, et al. Patterns of global gene expression in rat skeletal muscle during unloading and low-intensity ambulatory activity. Physiol Genomics 2003;13:157-67.

35 Cooper DM. Rethinking exercise testing in children: a challenge. Am J Respir Crit Care Med 1995; 152:1154-7.

36 Wasserman K, Whipp BJ, Koyl SN, et al. Anaerobic threshold and respiratory gas exchange during exercise. J Appl Physiol 1973;35:236-43.

37 Reybrouck T, Weymans M, Stijns H, et al. Ventilatory anaerobic threshold in healthy children. Age and sex differences. Eur J Appl Physiol Occup Physiol 1985;54:278-84.

38 Baba R, Nagashima M, Nagano Y, et al. Role of the oxygen uptake efficiency slope in evaluating exercise tolerance. Arch Dis Child 1999;81:73-5. 